\title{
Using Technology in Resource Limited Countries for Competency Based Education and Training
}

\section{WENDY ARNESON}

\begin{abstract}
Competency based education and training (CBET) helps to prepare graduates of medical laboratory science programs for the specific needs of the workforce. This is especially important in resourcelimited countries where shortage of laboratory personnel creates a large demand for skilled graduates. Internet and other technology can be useful to teach specific tasks in CBET. Even in resource-limited countries, technology can be used in the implementation of competency based education and training curricula in medical laboratory programs.
\end{abstract}

INDEX TERMS: competency based education and training, medical laboratory curriculum, principle learning outcomes, information and communication technology

\section{LEARNING OBJECTIVES}

1. Define competency based education and training (CBET)

2 Describe the curriculum needs in developing countries

3. Explain the process of CBET curriculum development for medical laboratory programs

4. Justify the use of internet and other technology in CBET curricula for medical laboratory programs

5. Describe an example CBET curriculum for a resource limited country

Clin Lab Sci 2010;23(3);182

Wendy Arneson, MS, MT (ASCP), ASCP Consultant, American Society for Clinical Pathology, Chicago, IL.

Address of Correspondence: Wendy L Arneson, MS, MT(ASCP), 9724 N Riverside Rd, Mequon, WI 53092, arnesonw@aol.com.

\section{INTRODUCTION}

Technology is useful in the implementation of competency based education and training (CBET) curriculum in medical laboratory programs, even in resource-limited countries. Uninterrupted power and access to internet are priorities in many medical laboratory programs in developing countries and students often have access to internet cafes and computer centers on and off campus. As students become aware of careers in medical laboratories in resource-limited countries, they want access to education and training that adequately prepares them for the workforce and provides opportunities for advancement. Competency based education and training often meets those needs since it provides for the education aspect, the knowledge and moral development, and the training aspect, supervised practice for proficiency in a skill or profession.

First, an introduction to CBET is helpful. Education is defined as to develop mentally, morally or aesthetically by instruction while training is defined as making prepared by exercise for a test of skill. Training is associated with psychomotor skills which require some motor activity which proceeds from mental activity. ${ }^{1}$ Medical laboratory professionals must draw upon critical thinking, ethical practices as well as hand-eye coordination in order to carry out even the most simple daily tasks and thus, medical laboratory education uses both education and training throughout the curriculum.

Traditional post-secondary education is often organized based on the knowledge and subject matter to be taught in a specific time interval. The course leader determines which learning objectives should be addressed within a semester and develops a list of topical lectures and supporting laboratory exercises. In CBET, the units of 


\section{FOCUS: EDUCATIONAL TECHNOLOGY}

instruction, course modules, are organized around learner mastery of specific tasks and knowledge to achieve competency. In order for CBET to be effective, the competencies are selected based on specific needs that all learners should master, provided sufficient time and appropriate educational methods are used. CBET is often described as learner outcome oriented rather than teacher and time oriented. ${ }^{2}$

Competency based education and training are concentrated on outcomes connected with scope of practice. Outcomes are taught with increasing complexity so that foundational knowledge can be built upon. ${ }^{3}$ Competencies taught in CBET are measured using benchmark assessments, provide for individual development of student performance, and ideally, allow for individual student-paced instruction. ${ }^{2,4,5}$ Competency-based education and training are considered more efficient in many programs, including businesses and industries that have been built around the competencybased model. ${ }^{6,7}$

\section{Curriculum needs in Developing Countries}

Many developing countries suffer from a lack of skilled medical laboratorians coupled with an increasing demand for laboratory services. The cost of postsecondary education, while significantly less than in developed countries, still represents a significant barrier to students in long-term educational programs. Likewise, access is limited. Some larger countries, such as Tanzania, have rapidly increased the number of health care facilities which provide laboratory services at the primary, secondary, tertiary, or reference healthcare levels and have clearly defined occupational roles for each level. Thus, education and training in developing countries should take into consideration laboratory scope of practice and provide for the needs of the healthcare system. In addition, curricula that address career laddering serve both the healthcare system and the individual's needs.

As an example, Tanzania has developed CBET medical laboratory curricula to provide for laboratory technicians with competencies to meet the needs of three tiers of laboratory service. For example, a module from the $2^{\text {nd }}$ year of the MLT curriculum is named "Laboratory Specimen Collection and Transportation."
Students are given time in this module to develop competencies in seven outcomes. One outcome and its four associated tasks is shown in Table 1. A module from the third year of the MLT curriculum is named "Laboratory Quality System Management." Students are provided with time to gain competencies in eleven outcomes. One of these outcomes and its associated tasks are shown in Table 2. These national standardized CBET curricula are based on specific scope of practice and help to supply more laboratorians at each tier of service.

Table 1. One Outcome and the Associated Tasks from $2^{\text {nd }}$ Year MLT Course Module

Outcome Number 2.1. Use specimen collection equipment and laboratory ware correctly and with care.

Tasks for Outcome 2.1:

a) identify specimen collection equipment and laboratory ware

b) Explain the function of specimen collection equipment and laboratory ware

c) Explain the steps for use of specimen collection equipment and laboratory ware

d) Use specimen collection equipment and laboratory ware according to procedures

Table 2. One Outcome and the Associated Tasks from $3^{\text {rd }}$ Year MLT Course Module

Outcome Number 3.1. Describe quality essential at the preanalytical phase.

Tasks for Outcome 3.1:

a) Explain pre-analytical phase of the quality assurance cycle

b) List quality system essentials of the pre-analytical phase

c) Describe proper packaging, storage and transportation of laboratory specimens

d) Explain personnel competence assessment

e) Describe laboratory services at a regional level with the use of an organogram

f) Describe procedures for laboratory biosafety and containment

g) Explain the importance of preparing and recording on temperature charts

Process of CBET development for Medical Laboratory Programs

Competency based education and training originated in vocational training in the late 1970s but are gradually becoming incorporated into other educational settings. ${ }^{8}$ The competency approach is commonly employed in 


\section{FOCUS: EDUCATIONAL TECHNOLOGY}

undergraduate and postgraduate public health and medical education in many countries including US, UK, New Zealand, and Australia.,10 This approach is also being used in medical laboratory programs in Eastern and Southern Africa. The curriculum must address the mission of the educational program, which is to provide entry level medical laboratorians for the laboratory service. Functional analysis of the occupational roles, referring to governmental job descriptions, the national laboratory strategic plan, and standardized test menus helps to clarify the mission statement. Instructional goals and objectives can be developed to further capture the means by which an educational program will implement its stated mission, as specified in accreditation criteria. The goal of professional education clarifies the intent of the educational program to produce graduates who are able to apply core educational knowledge. ${ }^{11}$

The first step of a competency based curriculum is to develop outcomes that address the needs of the profession. ${ }^{12}$ These outcomes are often subdivided into principal learning outcomes (PLO), enabling outcomes (EO), and sub-enabling outcome (SEO) statements. It is helpful to first order PLOs from basic to complex so that organization into units of instruction and programmatic structure is less difficult.

The next step is to develop tasks and competencies specifically for each SEO that are measurable behaviors. The most specific type of outcome statement is the task activity described as a learning objective. Since the tasks are written to be measurable behaviors, assessment is targeted to the task. Specifying the type of assessment for each behavior, as well as benchmarks or standards, helps to complete the competency based outcomes. Identifying the average number of instructional hours is helpful in the next step of forming the competencies into units of instruction and ultimately in forming the curriculum structure, particularly for student-paced instruction.

The third step is to cluster sub-enabling outcomes with their tasks into units of instruction such as course modules. This helps to organize competencies into related areas of expertise. The total instructional hours of the sub-enabling outcomes and tasks are added up to determine total instructional hours for each course module and can be converted to credit hours according to the formula provided by the institution. This information along with the assessment methods and other key information should be specified in the course module syllabi along with institutional requirements. Names of course modules will often take a more competency based approach rather than a subject based approach, e.g., Customer Care and Communication versus Laboratory Management.

The last step is to distribute course modules into programmatic structure based on weeks, semesters, quarters, or years to fit the institutional calendar. It is important, as with any curriculum, to consider prerequisite tasks and competencies addressed in earlier or co-current semesters. Outcomes within course modules should build on previous outcomes so that foundational knowledge and skills can be reinforced and applied to intermediate and advanced competencies.

In developing countries, new skill(s) are being introduced into laboratory service such as automation and the quality systems approach. To implement the competency based curriculum in developing countries, new technologies and competencies in the delivery of laboratory services should be taught to tutors, faculty, and clinical instructors. A program for training of trainers (TOT) can be part of the implementation stage of competency based curriculum.

\section{Role of Technology in Medical Laboratory Program CBET Curricula}

The use of information and communication technology (ICT) to enhance education has been ongoing in the USA for the past four decades. ${ }^{13}$ However ICT is valued in providing education in medical laboratory programs, one often assumes that technology is not available in developing countries. Nonetheless, medical laboratory education in developing countries has progressed from giving oral lectures, writing on the chalkboard, and demonstrating a few laboratory procedures to using computers, computer projectors, multi-head microscopes, digital microscopy, and the internet.

Technology provides excellent support for teaching competency-based education and training in that it can 


\section{FOCUS: EDUCATIONAL TECHNOLOGY}

help to clearly demonstrate principles that may be difficult to grasp with traditional teaching methods. Computerized presentation slides such as Microsoft PowerPoint ${ }^{\oplus}$ are being used for animated demonstrations, illustrating steps of a procedure, and creating job aids and handouts. These new technologies can assist in individual and group learning. ${ }^{14}$ Although most students in developing countries don't carry a laptop computer to class, they frequently do carry a flash drive with them. Students often have access to student computer centers or internet cafes on or near campus, so they appreciate the opportunity to receive the lecture notes and practice exercises on a flash drive after the presentation to view on a computer or to print out handouts for additional study. Although students are used to note-taking in class, these presentation notes can help to organize foundation knowledge and pose questions that lead toward application and critical thinking.

Some of the competencies in medical laboratory programs in developing countries involve method evaluation, research, and epidemiology projects. Medical laboratory students are taught how to search for literature and references for their research projects and to write scientific papers. Internet technology is becoming available in some universities and medical laboratory schools to provide access to online journals and periodicals, animated demonstrations and video clips, and online textbooks. This is especially helpful to medical laboratory programs since library resources in many cases are either absent or severely outdated. Access to internet resources gives them an economical way to support their research projects. However, using internet resources should not encourage a "cut and paste" mentality in students. Educational standards expect that students writing research papers do more than gather information or "scoop and smush, copy and paste" when they research. ${ }^{15}$

Online textbooks are available that are extremely helpful to medical laboratory faculty and students in resource limited countries, particularly when appropriate textbooks are expensive, become obsolete quickly, or are difficult to find. Some examples include the online biotechnology textbooks and a microbiology textbook at URL:
- http://www.ncbi.nlm.nih.gov/About/primer/index. html

- http://www.ncbi.nlm.nih.gov/bookshelf/br.fcgi? book=mboc4.

- http://pathmicro.med.sc.edu/book/welcome.htm

This paper provided information about use of technology in competency based education and training in medical laboratory programs in resource limited countries. This information may be useful to medical laboratory educators in the USA as they consider approaches and make decisions for competency-based program planning and curriculum development.

\section{REFERENCES}

1. Merriam-Webster Online Dictionary. 11 $1^{\text {th }}$ Edition. 2010. Merriam-Webster, Inc. URL: http://www.marriam-webster. com Accessed 5/1/2010.

2. Thomson P. Competency-Based Training: Some Development and Assessment Issues for Policy Makers. 1991. TAFE National Centre for Research and Development: Leabrook, Australia. ERIC: ED 333231.

3. Competencies and Learning Objectives. Council on Education for Public Health, Distribution authorized: February 19, 2006. URL: http:// www.ceph.org. Accessed 3/1/2010.

4. Norton RE. Competency-Based Education and Training: A Humanistic and Realistic Approach to Technical and Vocational Instruction. 1987. Paper presented at the Regional Workshop on Technical/Vocational Teacher Training in Chiba City, Japan. ERIC: ED 279910.

5. Foyster J. Getting to Grips with Competency-Based Training and Assessment. 1990. TAFE National Centre for Research and Development: Leabrook, Australia. ERIC: ED 317849.

6. Watson A. Competency-Based Vocational Education and SelfPaced Learning. 1990. Monograph Series, Technology University: Sydney, Australia. ERIC: ED 324443.

7. Delker PV. Basic Skills Education in Business and Industry: Factors for Success or Failure. 1990. Contractor Report, Office of Technology Assessment, United States Congress.

8. Power L., Cohen J. Competency-Based Education and Training Delivery: Status, Analysis and Recommendations. 2005. USAID. URL: http://pdf.usaid.gov/pdf_docs/PNAD P013. pdf

9. Wai-Ching L. Competency based medical training: review. BMJ 2002;325:693-6.

10. Woodhouse L, Cardelle L, Godin S, Shive S, et al. Transforming a Master of Public Health Program to Address Public Health Practice Needs. Prev Chronic Dis 2006;3(1): 16. URL http://www.cdc.gov/pcd/issues/2006/jan/05_0099. htm.

11. Council on Education for Public Health, Report February 2006. URL: http:// www.ceph.org. Accessed 3/1/2010.

12. Sullivan RS, McIntosh N. The Competency-Based Approach to Training. JHPIEGO Strategy Paper 1995. JHPIEGO 
Corporation. URL: http://www.reproline.jhu.edu/english/ Gread/6training/cbt/cbt.htm\#References. Accessed 3/1/2010.

13. Watson D. Understanding the relationship between ICT and education means exploring innovation and change. Educ Inf Technol 2006;11:199-216.
14. Greer R, Bares A. Beyond media stickiness and cognitive imprinting: Rethinking creativity in cooperative work \& learning with ICTs. Educ Inf Technol. 2007;12:123-36.

15. McKenzie J. Beyond Cut-and-Paste: Engaging Students in Wrestling with Questions of Import. From Now On: the educational technology journal. 2008; 18 (1) URL: http://www.fno.org Accessed 03/01/2010.

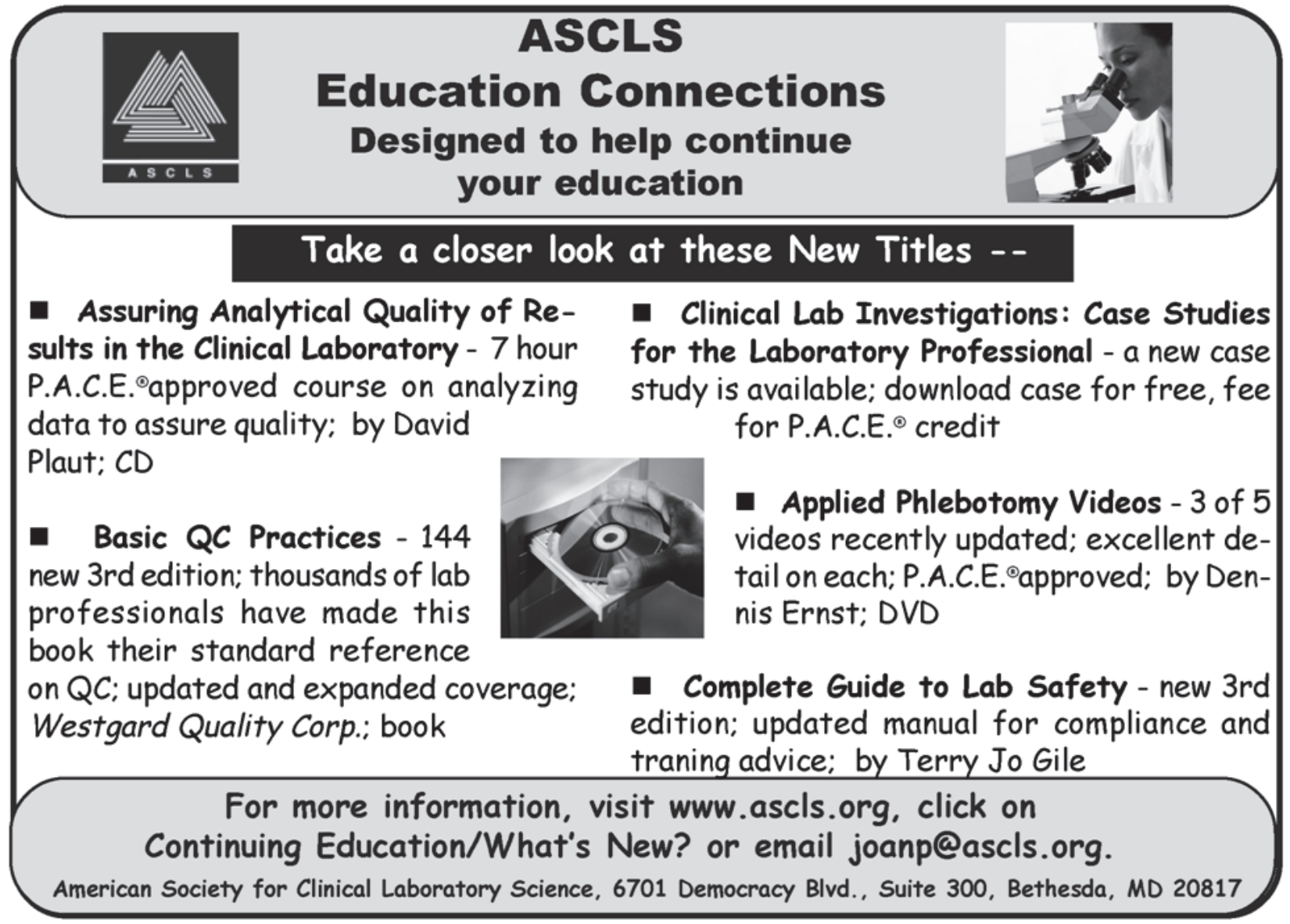

